\title{
Cytochalasin B induces apoptosis through the mitochondrial apoptotic pathway in HeLa human cervical carcinoma cells
}

\author{
JIYOUNG HWANG ${ }^{1}$, MYEONGJIN YI ${ }^{1}$, XIN ZHANG $^{1,2}$, YI XU ${ }^{1}$, JEE H. JUNG ${ }^{3}$ and DONG-KYOO KIM ${ }^{1}$ \\ ${ }^{1}$ Department of Biomedicinal Chemistry and Institute of Basic Science, Inje University, Gimhae, South Gyeongsang 621-749, \\ Republic of Korea; ${ }^{2}$ School of Life Science and Biopharmaceutics, Shenyang Pharmaceutical University, Shenyang, \\ Liaoning 110016, P.R. China; ${ }^{3}$ College of Pharmacy, Busan National University, \\ Geumjeong-gu, Busan 609-735, Republic of Korea
}

Received March 22, 2013; Accepted May 21, 2013

DOI: $10.3892 /$ or.2013.2617

\begin{abstract}
Cytochalasin B (CB) is a cell-permeable mycotoxin. It inhibits cytoplasmic division by blocking the formation of contractile microfilaments, it inhibits cell movement and induces nuclear extrusion. In the present study, we investigated the anticancer activity of CB in HeLa human cervical carcinoma cells. $\mathrm{CB}$ showed significant cytotoxicity, with an $\mathrm{IC}_{50}$ of $7.9 \mu \mathrm{M}$, in a WST-8 assay and significantly inhibited cell proliferation.Furthermore, results from Annexin V-FITC/propidium iodide double-staining indicated that $\mathrm{CB}$ induced early apoptosis of HeLa cells in a time-dependent manner. The cells exhibited apoptotic morphology, including cell shrinkage and nuclear condensation. CB induced cell cycle arrest at the $\mathrm{S}$ phase. We also observed inhibition of DNA replication in a $\left[{ }^{3} \mathrm{H}\right]$-thymidine incorporation assay. Furthermore, CB induced a time-dependent increase in reactive oxygen species and a decrease in mitochondrial membrane potential. Western blot analysis showed an increase in levels of mitochondrial factors Bax and Bcl-2, which was followed by activation of caspase- 9 and -3 . These results suggested that $C B$ induced apoptosis via a mitochondrial-dependent pathway in HeLa cells.
\end{abstract}

\section{Introduction}

In recent years, it has become apparent that reactive oxygen species (ROS) play an important role during induction of apoptotic cell death (1). $\mathrm{ROS}$, such as $\mathrm{H}_{2} \mathrm{O}_{2}$ and $\mathrm{O}_{2}^{-}$, are constantly produced during metabolic processes in all living species. Under physiological conditions, the maintenance of an appropriate level of intracellular ROS is important in maintaining redox balance and cell proliferation $(2,3)$. However,

Correspondence to: Professor Dong-Kyoo Kim, Department of Biomedicinal Chemistry and Institute of Basic Science, Inje University, 607 Aubang-dong, Gimhae, South Gyeongsang 621-749, Republic of Korea

E-mail: chemkdg@inje.ac.kr

Key words: cytochalasin B, apoptosis, cell cycle arrest, reactive oxygen species, mitochondrial pathway excessive ROS accumulation leads to cellular injury, including lipid peroxidation, protein oxidation, enzyme inactivation (4) and oxidative DNA damage $(5,6)$.

An increase in ROS generation is a common feature of cancer cells. Evidence suggests that most cancer cells are under oxidative stress that is associated with increased metabolic activity and production of ROS (7). Several studies have provided evidence that intracellular production of ROS can lead directly to activation of mitochondrial permeability transition, loss of mitochondrial membrane potential $(\Delta \Psi \mathrm{m})$, and cytochrome $c$ release from mitochondria into the cytoplasm, which is followed by activation of the caspase cascade and, ultimately, apoptotic cell death (8).

Morphologically, apoptosis is characterized by shrinkage of the cell, dramatic reorganization of the nucleus, active membrane blebbing and fragmentation of the cell into membrane-enclosed vesicles (apoptotic bodies) (9). In the early stage of apoptosis, the membrane phospholipid phosphatidylserine (PS) is translocated from the inner to the outer leaflet. Annexin V has a high affinity for PS, which identifies apoptosis at this early stage (10).

Apoptosis has been characterized as a fundamental cellular activity that maintains physiological balance within the organism (11). It is involved in immune defense mechanisms that play a necessary role in protecting against carcinogenesis by eliminating damaged or abnormal excess cells which have proliferated owing to the induction of various chemical agents $(12,13)$. The process of apoptosis is well regulated, requiring extracellular (extrinsic) and intracellular (intrinsic) inducers.

Upon intrinsic apoptotic stimulation, several important events occur in the mitochondria, including the release of cytochrome $c$ from the mitochondria into the cytoplasm $(14,15)$. Cytochrome $c$ binds to apoptotic protease activating factor 1 (Apaf-1), which then recruits procaspase-9 to form an apoptosome. This complex activates caspase-9, which in turn cleaves and activates effector procaspases to yield active effector caspases, such as caspase-3 (16). The Bcl-2 family of proteins plays an important role in the mitochondrial pathway of apoptosis; specifically, activation of mitochondria and release of intermembrane contents of mitochondria are under regulatory control of a number of Bcl-2 family proteins $(17,18)$. 
Anti-apoptotic proteins, including Bcl-2, prevent the release of cytochrome $c$ and pro-apoptotic proteins, such as Bax, promote the release of cytochrome $c$. The extrinsic pathway initiated by activation of the Fas receptor (also known as Apo-1 or CD95) involves a series of death-associated molecules, including the Fas-associated death domain-containing protein (FADD), an adaptor protein that is recruited to the Fas receptor upon its engagement $(19,20)$. FADD binds to and activates procaspase-8.

Marine invertebrates, such as sponges, tunicates and jellyfish, exhibit complex association with diverse microorganisms that are recognized as a prolific source of biologically active molecules, some of which have effects on cell viability and proliferation (21). One of these molecules, cytochalasin B (CB; Fig. 1) was isolated from Phoma sp. fungus obtained from the giant jellyfish Nemopilema nomurai (22). This toxin interferes with cytoskeleton functions by inhibiting actin polymerization $(23,24)$. At sufficiently high concentrations, cytochalasin poisoning of cells leads to a number of morphological and functional effects, including arborization, inhibition of endocytosis and secretion, suppression of cytoplasmic division and enucleation $(25,26)$. Moreover, in a previous study by Kulms et al (27), CB was shown to cause apoptosis via the extrinsic pathway. In the present study, we found that $\mathrm{CB}$ exhibited a marked cytotoxic effect on HeLa cells via caspase activation during apoptosis and we investigated the underlying mechanism. Our results indicate that CB elicits apoptosis via both the extrinsic and the intrinsic pathways.

\section{Materials and methods}

Chemicals. CB was a gift from Dr J.H. Jung. CB was dissolved in dimethyl sulfoxide (DMSO). Eagle's minimum essential medium (EMEM), penicillin and trypsin-EDTA were purchased from HyClone (Logan, UT, USA). Fetal bovine serum (FBS) was obtained from Gibco-BRL (Carlsbad, CA, USA). Cell Counting Kit-8 (CCK-8) was obtained from Dojindo (Japan). The propidium iodide (PI)/RNase staining buffer and Annexin-FITC kit for apoptosis were from BD Pharmingen (San Diego, CA, USA).

Cell culture. HeLa cells were obtained from the American Type Culture Collection (ATCC, Manassas, VA, USA) and were cultured in EMEM supplemented with $10 \% \mathrm{FBS} 37^{\circ} \mathrm{C}$ in a humidified atmosphere with $5 \% \mathrm{CO}_{2}$.

Cell viability and proliferation assay. HeLa cells were plated at $5 \times 10^{3}$ cells/well in a 96-well microplate. After $24 \mathrm{~h}$, media were substituted by fresh media containing $\mathrm{CB}$ at various concentrations $(5,10,20$ and $40 \mu \mathrm{M})$. The plate was incubated for a further $48 \mathrm{~h}$ and the cell viability was then assessed using a WST-8 assay according to the manufacturer's recommendations. The optical density for living cells was read at $450 \mathrm{~nm}$ in a multimicroplate reader (Synergy HT; BioTek Instruments, Inc. Winooski, VT, USA) (28). For the cell proliferation assay, cells were seeded at $5 \times 10^{3}$ cells $/ \mathrm{ml}$ media into 96 -well plates and treated with or without $\mathrm{CB}(8 \mu \mathrm{M})$ for various time periods.

Annexin V-FITC/PI apoptotic analysis. Cells $\left(5 \times 10^{5}\right.$ cells in a 60-mm petri dish), treated with or without $\mathrm{CB}$, were collected

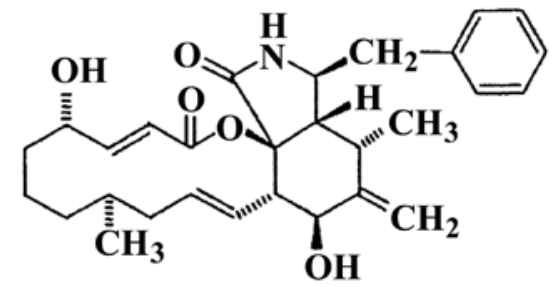

Figure 1. Chemical structure of cytochalasin B.

by trypsinization and washed with ice-cold phosphate buffered saline (PBS) via centrifugation. Then, $1 \times 10^{5}$ cells were resuspended in $100 \mu \mathrm{l}$ of binding buffer and stained with $5 \mu \mathrm{l}$ of Annexin V-FITC and $10 \mu \mathrm{l}$ of PI $(50 \mu \mathrm{g} / \mathrm{ml})$ for $15 \mathrm{~min}$ at room temperature, in the dark. Analysis was performed by FACSCalibur flow cytometer (Becton-Dickinson, San Jose, CA, USA) with 10,000 events/analysis. The data were analyzed using CellQuest software (Becton-Dickinson Instruments, Franklin Lakes, NJ, USA).

Measurement of apoptotic cell morphology. HeLa cells were distributed $\left(1 \times 10^{5}\right.$ cells/well) into a 24 -well plate and allowed to adhere overnight. The cells were treated with CB $(8 \mu \mathrm{M})$ for 24 and $48 \mathrm{~h}$. Non-treated wells received an equivalent volume of DMSO $(<0.1 \%)$ as control. Optic phase-contrast images were captured with a Phase Contrast-2, ELWD 0.3 inverted microscope (Nikon, Japan).

DNA content analysis. Cells $\left(3 \times 10^{5}\right.$ cells in a $60-\mathrm{mm}$ petri dish), treated with or without $\mathrm{CB}$, were collected by trypsinization and washed with ice-cold PBS via centrifugation. The cells were suspended in PBS and fixed with 70\% ethanol (v/v). Samples were washed with ice-cold PBS and stained with $\mathrm{PI} / \mathrm{RNase}$ staining buffer for $15 \mathrm{~min}$ at room temperature. The number of cells in different phases of the cell cycle was analyzed using a FACScan flow cytometer analysis system. The percentage of cells in the different phases of cell cycle was determined using Modifit software (Becton-Dickinson Instruments).

$\left[{ }^{3} \mathrm{H}\right]$-thymidine incorporation assay. The $\left[{ }^{3} \mathrm{H}\right]$-dTTP incorporation assay was performed as previously described (29). Briefly, HeLa cells were applied to 12 -well plates in growth medium. After the cells had grown to $70-80 \%$ confluence, they were rendered quiescent by incubation for $24 \mathrm{~h}$ in EMEM containing $2 \%$ FBS. Cells were treated with or without CB in EMEM supplemented with 10\% FBS and the cultures were then incubated for 21 or $45 \mathrm{~h} \cdot\left[{ }^{3} \mathrm{H}\right]-\mathrm{dTTP}$ was added at $1 \mu \mathrm{Ci} / \mathrm{ml}$ $(1 \mu \mathrm{Ci}=37 \mathrm{kBq})$ and incubated for a further $3 \mathrm{~h}$. Incorporated $\left[{ }^{3} \mathrm{H}\right]$-dTTP was extracted in cell lysis buffer and measured in a liquid scintillation analyzer (Tris-Crab 2910TR; Perkin-Elmer Inc., Waltham, MA, USA).

Measurement of intracellular ROS. Generation of ROS was assessed by using the fluorescent indicator 2,7-dichlorodihydrofluorescein ( $\left.\mathrm{H}_{2} \mathrm{DCFDA}\right)$, a cell-permeable indicator for ROS shown to react with $\mathrm{H}_{2} \mathrm{O}_{2}$ (30). As previously described, $\mathrm{H}_{2}$ DCFDA was oxidized to highly green fluorescent 2,7-dichlorofluorescein (DCF) by the generation of ROS. Cells 

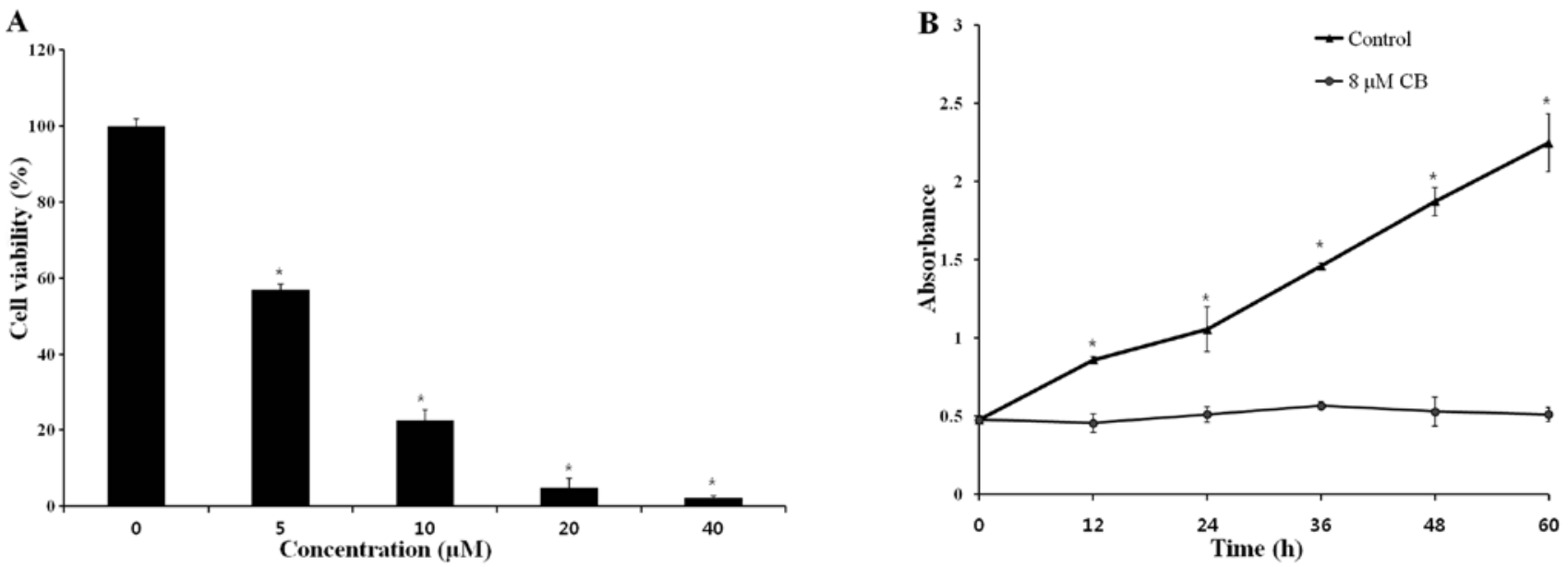

Figure 2. Effects of cytochalasin B (CB) on HeLa cell cytotoxicity and proliferation. (A) HeLa cells were treated with CB at different concentrations $(0-40 \mu \mathrm{M})$ for $48 \mathrm{~h}$. Cell viability was determined by the WST- 8 assay. (B) HeLa cells were treated with either vehicle alone or $8 \mu \mathrm{M} \mathrm{CB}$ at different times (0-60 h). The data are expressed as means $\pm \mathrm{SD}, \mathrm{n}=3$. ${ }^{*} \mathrm{P}<0.05$, significantly different from the control at the same level.

$\left(3 \times 10^{5}\right.$ cells in a $60-\mathrm{mm}$ petri dish), treated with or without $\mathrm{CB}$, were collected by trypsinization and centrifugation. Samples were washed with ice-cold PBS and stained with $2 \mu \mathrm{l}$ $\mathrm{H}_{2} \mathrm{DCFDA}$ for $30 \mathrm{~min}$ at $37^{\circ} \mathrm{C}$ in a dark room. Relative fluorescence intensities were monitored using the FACSCalibur flow cytometer and analyzed using CellQuest software with the FL-1 channel (green) set to $530 \mathrm{~nm}$.

Measurement of $\Delta \Psi m$. Depolarization of the mitochondrial membrane was detected using a fluorescent probe, rhodamine 123. During apoptosis, the integrity of the mitochondrial membrane is disrupted, which leads to depolarization of the membrane and opening of mitochondrial permeability transition pores and release of sequestered rhodamine 123. Cells $\left(3 \times 10^{5}\right.$ cells in a $60-\mathrm{mm}$ petri dish), treated with or without $\mathrm{CB}$, were collected by trypsinization and centrifugation. Samples were washed with ice-cold PBS and stained with $5 \mu 1$ rhodamine 123 for $30 \mathrm{~min}$ at $37^{\circ} \mathrm{C}$ in a dark room. Relative fluorescence intensities were monitored using a FACSCalibur flow cytometer and analyzed using CellQuest software with the FL-1 channel.

Western blot analysis. After cells were treated with or without $\mathrm{CB}$, total cell lysates and cytosolic fractions were prepared as previously described (31). Protein contents of the lysates were determined by the Bradford protein assay (Bio-Rad, Hercules, CA, USA). Proteins ( $30 \mu \mathrm{g}$ ) were resolved by sodium dodecyl sulfate polyacrylamide gel electrophoresis (SDS-PAGE) and transferred onto nitrocellulose membranes (Schleicher \& Schuell, BioScience, Inc., Keene, NH, USA) by western blotting. The results were quantified using Image J v. 1.43 software (National Institutes of Health, Bethesda, MD, USA). The following primary polyclonal antibodies were used: $\beta$-actin, Bcl-2, caspase-9, caspase-8 (1:1,000 dilution; Cell Signaling Technology Inc, Danvers, MA, USA), caspase-3, p53 (1:300; Santa Cruz Biotechnology, Inc., Santa Cruz, CA, USA) and Bax (1:1,000; BD Pharmingen, San Diego, CA, USA).

Statistical analysis. All results reported were obtained from at least 3 independent experiments with similar results and the results are expressed as means \pm standard deviation (SD) in quantitative experiments. Statistical analysis was performed by one-way analysis of variance (ANOVA). $\mathrm{P}<0.05$ was considered to indicate a statistically significant difference. Microsoft Excel 2007 was used for statistical and graphical evaluations.

\section{Results}

$C B$ inhibits cell viability. In the present study, we investigated the cytotoxicity of 48-h treatment with various concentrations $(5,10,20$ and $40 \mu \mathrm{M})$ of $\mathrm{CB}$ on the growth of HeLa human cervical carcinoma cells, using a WST-8 assay. As shown in Fig. 2A, CB inhibited cell viability, with an $\mathrm{IC}_{50}$ of $\sim 7.9 \mu \mathrm{M}$. Treatment of HeLa cells with $8 \mu \mathrm{M}$ of CB for $0,12,24,36,48$ and $60 \mathrm{~h}$, inhibited proliferation, whereas untreated cells maintained exponential proliferation (Fig. 2B). Thus, CB treatment significantly inhibited growth of HeLa cells in both a concentration- and a time-dependent manner. These data indicate that CB may suppress cancer cell proliferation or induce cancer cell apoptosis, leading to growth-inhibition of cancer cells.

CB induces apoptosis. Light microscopy revealed morphological characteristics of apoptosis in cells treated with an $\mathrm{IC}_{50}$ concentration of $\mathrm{CB}$ at various time points. As shown in Fig. 3A, untreated cells spread regularly throughout the culture plates and grew to near confluence. After $24 \mathrm{~h}$ of treatment, the cells showed a decrease in size and rounding up of cells, with increased intercellular spaces, but the majority of the attached cells retained a normal cellular shape. After $48 \mathrm{~h}$ of treatment, the number of shrunk and floating cells increased, as did the intercellular spaces and distinct changes in morphology were observed.

Further evidence for the activation of apoptosis was obtained by double-staining of cell cultures with PI and Annexin V-FITC. Annexin V is a protein that binds to PS, which is translocated from the inner to the outer membrane leaflet early in the apoptotic process, with high affinity. Significant differences were observed between the control and treated cells. As shown in Fig. 3B, 93.58\% of vehicle alone-treated HeLa cells were viable (Annexin $\mathrm{V}^{-} / \mathrm{PI}^{-}$) and 
A

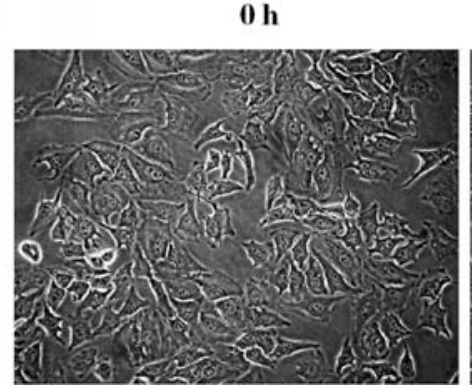

$24 \mathrm{~h}$

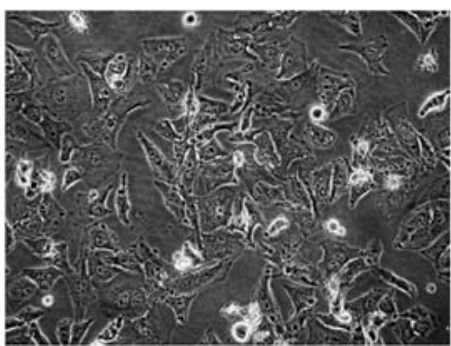

$48 \mathrm{~h}$

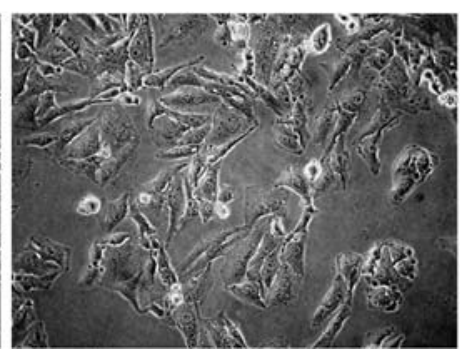

B

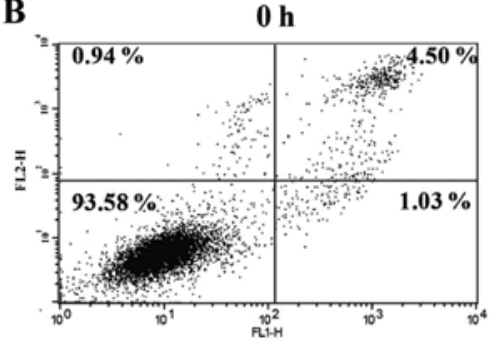

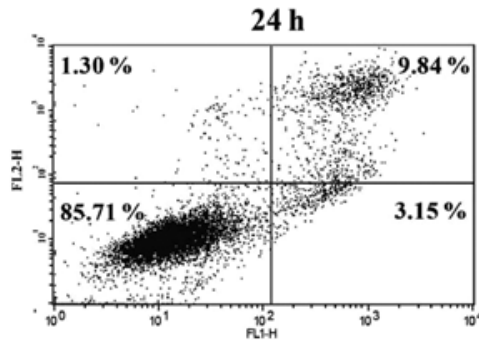

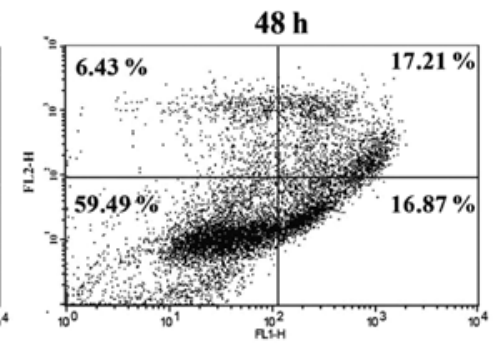

Figure 3. Cytochalasin B (CB) induces apoptosis of HeLa cells. (A) The morphology of HeLa cells after exposure to CB for different times (0, 24, $48 \mathrm{~h})$ was examined and photographed by the inverted light microscope. Cell damage appeared after treatment with $8 \mu \mathrm{M} \mathrm{CB}$, compared with the control. All experiments were performed in triplicate and gave similar results. Magnification, x160. (B) Flow cytometric analysis of Annexin V-FITC/PI double-straining. HeLa cells were non-treated or treated for 24 and $48 \mathrm{~h}$ with $8 \mu \mathrm{M} \mathrm{CB}$.

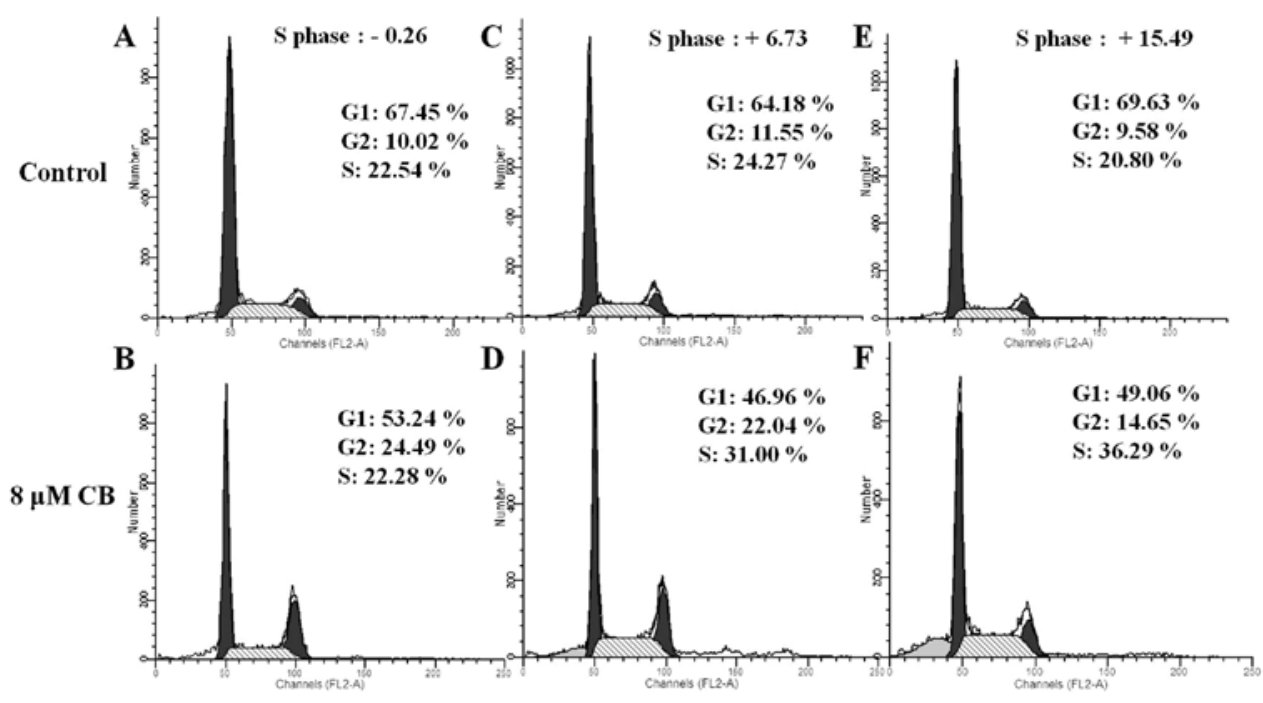

Figure 4. Effect of cytochalasin B (CB) on the cell cycle distribution of HeLa cells. HeLa cells were untreated for (A) $24 \mathrm{~h}$, (C) $36 \mathrm{~h}$ and (E) $48 \mathrm{~h}$. HeLa cells were treated with $8 \mu \mathrm{M} \mathrm{CB}$ for (B) $24 \mathrm{~h}$, (D) $36 \mathrm{~h}$ and (F) $48 \mathrm{~h}$. CB inhibited HeLa cell proliferation via S-phase arrest in a time-dependent manner. Cell cycle distribution was calculated as the percentage of cells in the $\mathrm{G} 1, \mathrm{~S}$ and $\mathrm{G} 2 / \mathrm{M}$ phase. The data are representative of 3 independent experiments.

$1.03 \%$ were early apoptotic cells (Annexin $\left.\mathrm{V}^{+} / \mathrm{PI}\right)$. However, after $48 \mathrm{~h}$ of treatment with $\mathrm{CB}$, the percentage of early apoptotic cells increased significantly from $3.15-16.87 \%$, and late apoptotic (or necrotic cells) cells increased from 9.84-17.21\%. Taken together, these findings provided evidence that $\mathrm{CB}$ induced apoptosis in HeLa cells.

$C B$ causes $S$-phase arrest. Cell growth and inhibition are both tightly regulated through cell cycle control (32) and dysregulation of cell cycle progression has been implicated in the initiation of apoptosis $(33,34)$. In order to further examine the effects of $\mathrm{CB}$ on the cell cycle, cell cycle distribution of
HeLa cells treated by $\mathrm{CB}(8 \mu \mathrm{M})$ was studied by investigating DNA content. As shown in Fig. 4, for all treatment durations, the percentage of cells in G2 phase was increased. At $36 \mathrm{~h}$, the percentage of cells in $\mathrm{S}$ phase was increased. These results suggest that CB inhibited HeLa cell proliferation, via S-phase arrest, in a time-dependent manner. We hypothesized that $\mathrm{CB}$ induced cell cycle arrest in $\mathrm{S}$ phase due to the inhibition of DNA replication. To confirm this hypothesis, we analyzed DNA replication in cells treated with $\mathrm{CB}$ by determining the incorporation of $\left[{ }^{3} \mathrm{H}\right]$-dTTP. As shown in Fig. 5, CB inhibited $\left[{ }^{3} \mathrm{H}\right]$-dTTP incorporation after 24 and $48 \mathrm{~h}$ of treatment by $\sim 50$ and $75 \%$, respectively. 


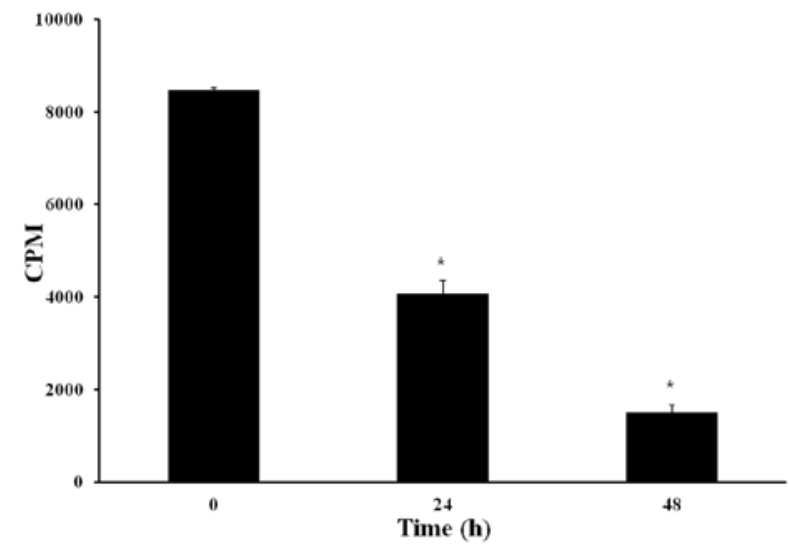

Figure 5. Inhibitory effect of cytochalasin B $(\mathrm{CB})$ on $\left[{ }^{3} \mathrm{H}\right]$-dTTP incorporation of HeLa cells. HeLa cells were treated with $8 \mu \mathrm{M} \mathrm{CB}$. The amount of $\left[{ }^{3} \mathrm{H}\right]$-dTTP incorporated was analyzed by scintillation counting. The data are expressed as means $\pm \mathrm{SD}, \mathrm{n}=3$. ${ }^{*} \mathrm{P}<0.05$, significantly different from the control at the same level.
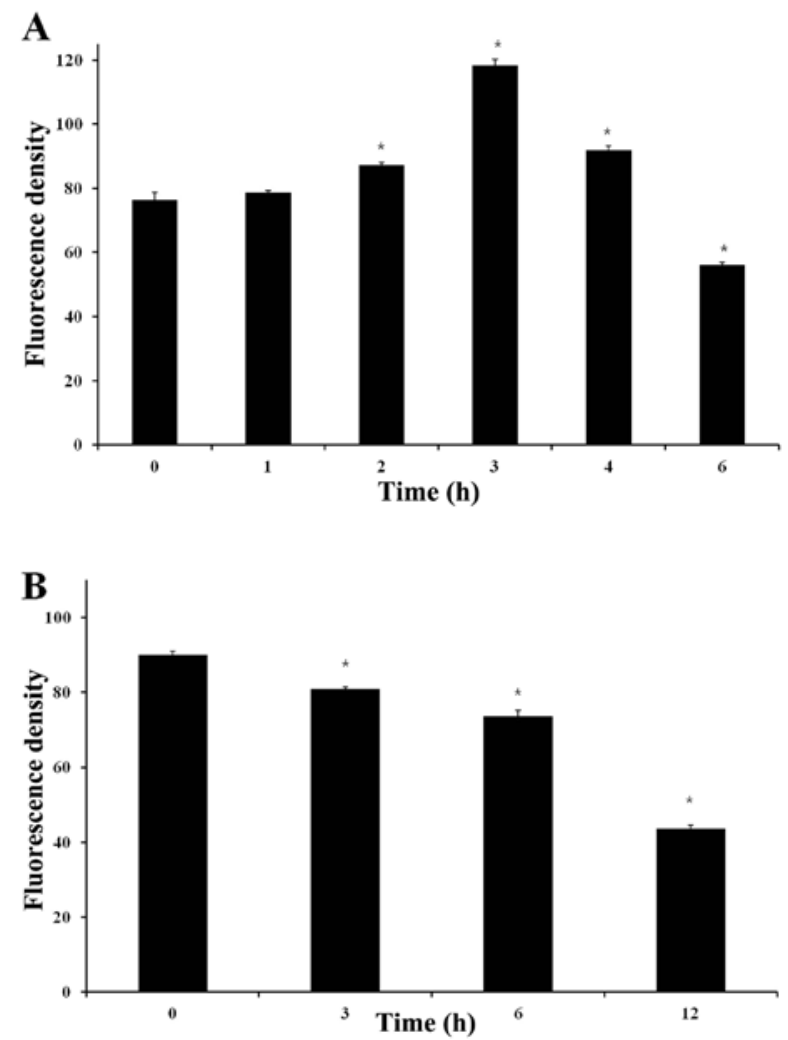

Figure 6. Effect of cytochalasin $\mathrm{B}(\mathrm{CB})$ on reactive oxygen species generation (A) and mitochondrial membrane potential (B) in HeLa cells at different time points. HeLa cells were treated with $8 \mu \mathrm{M}$ CB for various times. The data are expressed as means $\pm S D, n=3$. $P<0.05$, significantly different from the control at the same level.

$C B$ increases ROS and disrupts $\triangle \Psi m$. Several studies have reported that generation of ROS is associated with disruption of $\Delta \Psi \mathrm{m}$ (35). CB was found to be capable of generating intracellular ROS when examined by the cell permeable dye $\mathrm{H}_{2}$ DCF-DA. Treatment of cells for $3 \mathrm{~h}$ with $8 \mu \mathrm{M}$ of CB induced a change in ROS generation compared to control. Fig. 6A shows that the mean H2DCF-DA fluorescence increased from $\sim 76.48(0 \mathrm{~h})$ to $118.35(3 \mathrm{~h})$ after treatment with $8 \mu \mathrm{M}$ of CB.

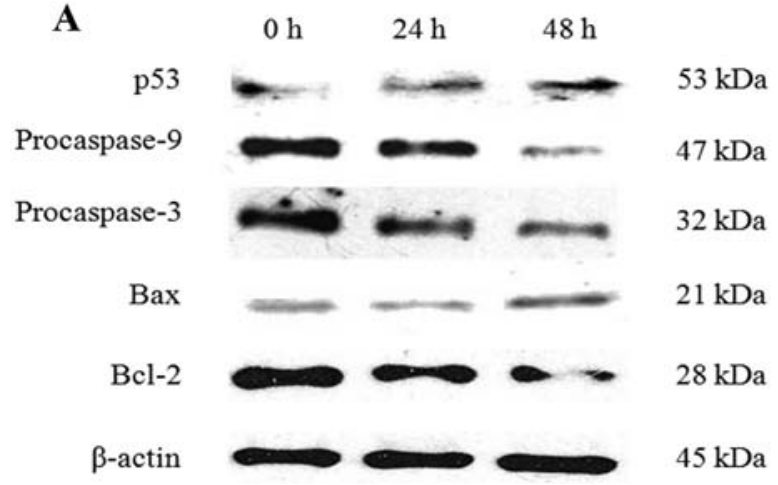

B
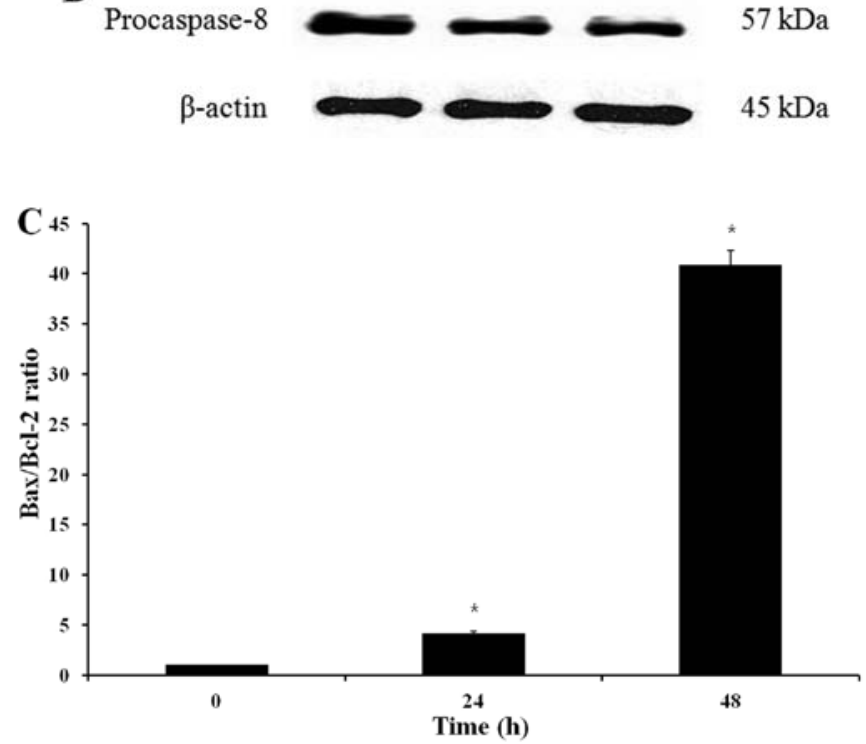

Figure 7. Western blot analysis of proteins involved in the mitochondrial pathway. HeLa cells were treated with $8 \mu \mathrm{M}$ cytochalasin B (CB) for 0 , 24 and $48 \mathrm{~h}$. The expression of proteins was analyzed by western blotting. (A) $\mathrm{CB}$ induced caspase activation and increased p53. CB regulated Bax and $\mathrm{Bcl}-2$ expressions in HeLa cells. (B) $\mathrm{CB}$ induced caspase- 8 activation in HeLa cells. (C) Ratio of Bax/Bcl-2. The data are expressed as means $\pm \mathrm{SD}$, $n=3 . ~ P<0.05$, significantly different from the control at the same level.

Mitochondrial membrane depolarization (MMP) is a known event associated with apoptosis. A decrease in $\mathrm{H}_{2}$ DCF-DA fluorescence indicates a loss of MMP. In this study, we detected loss of MMP after treatment of cells with CB by staining HeLa cells with rhodamine 123. Fig. 6B showed that the mean rhodamine 123 fluorescence decreased from $\sim 89.99$ $(0 \mathrm{~h})$ to $73.55(6 \mathrm{~h})$ and $43.63(12 \mathrm{~h})$ by treatment with $8 \mu \mathrm{M}$ of $\mathrm{CB}$, suggesting that mitochondria was involved in $\mathrm{CB}$-induced apoptosis.

CB-induced apoptosis is mediated via the mitochondrial pathway. The expression of apoptosis-related proteins was analyzed by western blotting. Fig. 7B shows that the expression of procaspase- 8 was decreased after $\mathrm{CB}$ treatment of HeLa cells. This is in agreement with a previous report by Kulms et al (27), who found that CB caused apoptosis via activation of $\mathrm{CD} 95$, the Fas receptor. To further characterize CB-induced apoptosis, we examined whether CB also activates the intrinsic apoptotic pathway in HeLa cells. 
CB induced activation of caspases, increased p53 levels, and regulated the expression of the pro-apoptotic protein Bax and the anti-apoptotic protein Bcl-2 (Fig. 7A). The Bcl-2 family proteins, Bax and $\mathrm{Bcl}-2$, play important roles in initiating the mitochondrial death cascade (36). In particular, protein expression of Bax was increased and that of Bcl-2 was decreased, resulting in an increase in the Bax/Bcl-2 ratio (Fig. 7C).

To determine which apoptotic pathway is activated by $\mathrm{CB}$, we examined the activity of procaspase- 8 and -9 , the important proteins in the extrinsic and intrinsic pathway, respectively. Collectively, these findings demonstrate that CB-induced apoptosis in HeLa cells is mediated via the mitochondrial pathway.

\section{Discussion}

Cytochalasin B (CB) is a cell-permeable mycotoxin. It inhibits cytoplasmic division by blocking the formation of contractile microfilaments. It inhibits cell movement and induces nuclear extrusion. In this study, we investigated the effects of $\mathrm{CB}$ on human cervical carcinoma HeLa cells. We found that $\mathrm{CB}$ inhibited HeLa cell proliferation, and induced S-phase arrest and apoptosis through the generation of ROS and the disruption of MMP. CB treatment significantly inhibited the growth of HeLa cells in both a concentration- and a time-dependent manner. $\mathrm{CB}$ exhibited inhibition on cell viability with an $\mathrm{IC}_{50}$ of approximately $7.9 \mu \mathrm{M}$ after $48 \mathrm{~h}$ treatment and inhibited proliferation, whereas untreated cells maintained an exponential proliferation state.

We analyzed DNA content using flow cytometry and found that $\mathrm{CB}$ inhibited HeLa cell proliferation via $\mathrm{S}$-phase arrest in a time-dependent manner. During the $S$ phase of the cell division cycle, cells replicate their DNA. If DNA replication is blocked by an inhibitor or if the template is damaged by radiation or other factors, signals are generated that can induce cell-cycle arrest or apoptosis (37). Therefore, we hypothesized that cell cycle arrest in $\mathrm{S}$ phase was induced due to the inhibition of DNA replication; this hypothesis was supported by our finding that $\left[{ }^{3} \mathrm{H}\right]$ thymidine incorporation was inhibited by CB treatment after 24 and $48 \mathrm{~h}$. Morphological changes of cell apoptosis were clearly observed, and the result of Annexin V-FITC/PI double-staining indicated that CB induced early apoptosis in HeLa cells.

Recent studies have reported that generation of ROS is associated with disruption of MMP, thereby triggering a series of mitochondrial-associated events, including apoptosis (35). In the present study, we found that CB induced HeLa cell apoptosis, which was associated with a significant increase in the levels of intracellular ROS and disruption of MMP. Based on these results, we performed western blot analysis to further investigate the apoptotic pathway activated in CB-treated HeLa cells. A direct link between ROS and apoptosis is possible as ROS production causes dimerization of Bax in the cytosol. The Bcl-2 family proteins Bax and Bcl-2 play important roles in initiating the mitochondria-mediated apoptotic pathway (36). Anti-apoptotic protein Bcl-2 prevents this process by preserving mitochondrial integrity. Thus, the ratio of Bax to Bcl-2 is crucial to sustaining drug-induced apoptosis in the mitochondria-mediated apoptotic pathway (38). The present study showed that $\mathrm{CB}$ upregulated the expression level of Bax and downregulated the expression level of Bcl-2, even- tually leading to an increase in the ratio of $\mathrm{Bax} / \mathrm{Bcl}-2$ protein levels. The release of mitochondrial cytochrome $c$ facilitates the formation of the apoptosome complex, consisting of Apaf-1 and caspase-9, which subsequently activates effector caspases, such as caspase-3 and leads to apoptosis (16). In the present study, activation of both caspase- 9 and -3 were detected. Moreover, the level of p53, a well-known tumor suppressor protein, increased. These results suggest that $\mathrm{CB}$ induced apoptosis via the mitochondria-dependent pathway.

In conclusion, the results of the present study revealed that CB inhibited proliferation of HeLa cells, by inducing arrest in the $S$ phase of the cell cycle and by inducing apoptosis through the generation of ROS and disruption of MMP. Although a previous study by Kulms et al (27) suggested that CB causes apoptosis via the extrinsic pathway, our findings suggest that $\mathrm{CB}$ activates the intrinsic apoptotic pathway. Therefore, $\mathrm{CB}$ triggers apoptosis via both the intrinsic pathway as well as the extrinsic pathway. The results of our study suggest that $\mathrm{CB}$ may suppress cancer cell proliferation or induce cancer cell apoptosis, inhibiting the growth of cancer cells.

\section{Acknowledgements}

This study was supported by the 2012 Inje University research grant.

\section{References}

1. Fleury C, Mignotte B and Vayssière JL: Mitochondrial reactive oxygen species in cell death signaling. Biochimie 84: 131-141, 2002.

2. Preeta R and Nair RR: Stimulation of cardiac fibroblast proliferation by cerium: a superoxide anion-mediated response. J Mol Cell Cardiol 31: 1573-1580, 1999.

3. Nicotera TM, Privalle C, Wang TC, et al: Differential proliferative responses of Syrian hamster embryo fibroblasts to paraquat-generated superoxide radicals depending on tumor suppressor gene function. Cancer Res 54: 3884-3888, 1994.

4. Morel I, Lescoat G, Cillard J, et al: Kinetic evaluation of freemalondialdehyde and enzyme leakage as indices of iron damage in rat hepatocyte cultures. Involvement of free radicals. Biochem Pharmacol 39: 1647-1655, 1990.

5. Randerath K, Randerath E, Smith CV and Chang J: Structural origins of bulky oxidative DNA adducts (type II I-compounds) as deduced by oxidation of oligonucleotides of known sequence. Chem Res Toxicol 9: 247-254, 1996.

6. Ames BN: Endogenous DNA damage as related to cancer and aging. Mutat Res 214: 41-46, 1989.

7. Szatrowski TP and Nathan CF: Production of large amounts of hydrogen peroxide by human tumor cells. Cancer Res 51: 794-798, 1991.

8. Chan WH, Wu CC and Yu JS: Curcumin inhibits UV irradiation-induced oxidative stress and apoptotic biochemical changes in human epidermoid carcinoma A431 cells. J Cell Biochem 90: 327-338, 2003.

9. Earnshaw WC: Nuclear changes in apoptosis. Curr Opin Cell Biol 7: 337-343, 1995.

10. Miao C, Du J, Dang HT, et al: Apoptotic activity of fatty acid derivatives may correlate with their inhibition of DNA replication. Int J Oncol 33: 1291-1298, 2008.

11. Zhang X, Zhao J, Kang S, et al: A novel cromakalim analogue induces cell cycle arrest and apoptosis in human cervical carcinoma HeLa cells through the caspase- and mitochondria-dependent pathway. Int J Oncol 39: 1609-1617, 2011.

12. Hengartner MO: The biochemistry of apoptosis. Nature 407: 770-776, 2000.

13. Brown JM and Wouters BG: Apoptosis, p53, and tumor cell sensitivity to anticancer agents. Cancer Res 59: 1391-1399, 1999.

14. Reed JC and Green DR: Remodeling for demolition: changes in mitochondrial ultrastructure during apoptosis. Mol Cell 9: 1-3, 2002 . 
15. Wang $\mathrm{C}$ and Youle RJ: The role of mitochondria in apoptosis Ann Rev Genet 43: 95-118, 2009.

16. Ghobrial IM, Witzig TE and Adjei AA: Targeting apoptosis pathways in cancer therapy. CA Cancer J Clin 55: 178-194, 2005.

17. Marzo I, Brenner C, Zamzami N, et al: The permeability transition pore complex: a target for apoptosis regulation by caspases and Bcl-2 related proteins. J Exp Med 187: 1261-1271, 1998.

18. Kuwana T and Newmeyer DD: Bcl-2-family proteins and the role of mitochondria in apoptosis. Curr Opin Cell Biol 15: 691-699, 2003.

19. Boldin MP, Varfolomeev EE, Pancer Z, et al: A novel protein that interacts with the death domain of Fas/APO1 contains a sequence motif related to the death domain. J Biol Chem 270: 7796-7798, 1995.

20. Chinnaiyan AM, O'Rourke KO, Tewari M and Dixit VM: FADD, a novel death domain-containing protein, interacts with death domain of Fas and initiates apoptosis. Cell 81: 505-512, 1995.

21. Wilkinson CR: Symbiotic interactions between marine sponges and algae. In: Algae and Symbioses. Reisser W (ed). Biopress, Bristol, pp112-151, 1992.

22. Kim EL, Li JL, Dang HT, et al: Cytotoxic cytochalasins from the endozoic fungus Phoma sp. of the giant jellyfish Nemopilema nomurai. Bioorg Med Chem Lett 22: 3126-3129, 2012

23. Spooner BS: Cytochalasins as probes in selected morphogenetic processes. In: Cytochalasins. Biochemical and Cell Biological Aspects. Tanenbaum SW (ed). Elsevier/North Holland Biomedical Press, Amsterdam, pp161-189, 1978.

24. Bonder EM and Mooseker MS: Cytochalasin B slows but does not prevent monomer addition at the barbed end of the actin filament. J Cell Biol 102: 282-288, 1986.

25. Foissner I and Wasteneys GO: Wide-ranging effects of eight cytochalasins and latrunculin A and B on intracellular motility and actin filament reorganization in characean internodal cells. Plant Cell Physiol 48: 585-587, 2007.

26. Ohmori H, Toyama S and Toyama S: Direct proof that the primary site of action of cytochalasin on cell motility processes is actin. J Cell Biol 116: 933-941, 1992.

27. Kulms D, Düssmann H, Pöppelmann B, et al: Apoptosis induced by disruption of the actin cytoskeleton is mediated via activation of CD95 (Fas/APO-1). Cell Death Differ 9: 598-608, 2002.
28. Tominaga $\mathrm{H}$, Ishiyama $\mathrm{M}$, Ohseto $\mathrm{F}$, et al: A water-soluble tetrazolium salt useful for colorimetric cell viability assay. Anal Commun 36: 47-50, 1999.

29. Lin SY, Liu JD, Chang HC, et al: Magnolol suppresses proliferation of cultured human colon and liver cancer cells by inhibiting DNA synthesis and activating apoptosis. J Cell Biochem 84: 532-544, 2002.

30. Bobyleva V, Pazienza TL, Maseroli R, et al: Decrease in mitochondrial energy coupling by thyroid hormones: a physiological effect rather than a pathological hyperthyroidism consequence. FEBS Lett 430: 409-413, 1998.

31. Qi F, Li A, Zhao L, et al: Cinobufacini, an aqueous extract from Bufo bufo gargarizans Cantor, induces apoptosis through a mitochondria-mediated pathway in human hepatocellular carcinoma cells. J Ethnopharmacol 128: 654-661, 2010.

32. Sánchez I and Dynlacht BD: New insights into cyclins, CDKs, and cell cycle control. Semin Cell Dev Biol 16: 311-321, 2005.

33. Lee S, Christakos S and Small MB: Apoptosis and signal transduction: clues to a molecular mechanism. Curr Opin Cell Biol 5: 286-291, 1993.

34. Smith DM, Gao G, Zhang X, et al: Regulation of tumor cell apoptotic sensitivity during the cell cycle (Review). Int J Mol Med 6: 503-507, 2000.

35. Park MT, Kim MJ, Kang YH, et al: Phytosphingosine in combination with ionizing radiation enhances apoptotic cell death in radiation-resistant cancer cells through ROS-dependent and -independent AIF release. Blood 105: 1724-1733, 2005.

36. Gross A, McDonnell JM and Korsmeyer SJ: BCL-2 family members and the mitochondria in apoptosis. Genes Dev 13 1899-1911, 1999.

37. Jiang YH, Ahn EY, Ryu SH, et al: Cytotoxicity of psammaplin A from a two-sponge association may correlate with the inhibition of DNA replication. BMC Cancer 4: 70, 2004.

38. Qi F, Inagaki Y, Gao B, et al: Bufalin and cinobufagin induce apoptosis of human hepatocellular carcinoma cells via Fas- and mitochondria-mediated pathways. Cancer Sci 102: 951-958, 2011. 